\title{
Formation Quality Optimization and Corrosion Performance of Inconel 625 Weld Overlay Using Hot Wire Pulsed TIG
}

\author{
Guo Longlong1, $\quad$ Zheng Hualin', Liu Shaohu², Li Yueqin ${ }^{1}, \quad$ Xu Xiaodong ${ }^{1}, \quad$ Feng \\ Chunyu ${ }^{1}$
}

${ }^{1}$ Southwest Petroleum University, Chengdu 610500, China; ${ }^{2}$ Yangtze University, Jingzhou 434023, China

\begin{abstract}
Based on the central composite rotatable design (CCD), clad beads of Inconel 625 were deposited on the surface of AISI 4130 plates using hot wire pulsed TIG (tungsten inert gas arc welding) technique. The response surface methodology (RSM) was used to establish models between process parameters and geometrical characteristics of the clad beads. Then, multiple-track two-layer weld overlay was deposited using the optimized process parameters. The microstructure of the weld overlay is primarily composed of columnar dendrites, and there are also a few planar crystals and cellular dendrites near the fusion zone. Meanwhile, equiaxed grains and steering dendrites are mainly distributed in the upper portion of the weld overlay. Potentiodynamic polarization tests were used to evaluate the corrosion resistance of the weld overlay and the substrate. The results show that adding clad layers can enhance the corrosion resistance, which degrades with the increase in Fe dilution. Moreover, the corrosion resistance of the second layer surface is close to that of wrought Inconel 625.
\end{abstract}

Key words: Inconel 625; response surface methodology; microstructure; weld overlay; potentiodynamic polarization

Inconel 625 exhibits excellent performances, such as favorable strength even at high temperature, satisfactory welding workability, and good corrosion resistance ${ }^{[1-3]}$. These outstanding properties primarily issue from the solid solution hardening of molybdenum and niobium in its austenitic fcc matrix ${ }^{[4,5]}$. The favorable mechanical properties are also caused by precipitation hardening of fine metastable $\gamma^{\prime \prime}\left(\mathrm{Ni}_{3} \mathrm{Nb}\right)$ after annealing over a long period at a high temperature ${ }^{[6]}$. Additionally, the presence of chromium and nickel protect it against oxidizing environment, while molybdenum and nickel resist any form of non-oxidizing corrosion ${ }^{[7]}$. Niobium provides favorable resistance to chloride stress corrosion cracking $^{[8]}$. For above advantages, Inconel 625 has been extensively used in oil and gas, nuclear power, marine, aerospace, and chemical industry ${ }^{[7,9]}$. Nevertheless, high production cost has minimized the bulk individual application of this alloy. Fortunately, the high ductility of the Inconel 625 boosts its welding ability, which prevents solidification cracking after welding ${ }^{[10]}$. Therefore, cladding Inconel 625 on the surfaces, which suffer with aggressive corrosive medium, is an available and economical method without comprising the corrosion property.

Most of the previous studies on the Inconel 625 weld overlay were performed using various methods, such as traditional TIG, explosive welding, plasma arc welding, and laser beam welding. J. N. DuPont ${ }^{[11]}$ studied the solidification behavior of alloy Inconel 625 coating surfaced on $2.25 \mathrm{Cr}-1 \mathrm{Mo}$ steel using TIG technology. The results indicated that the solidification reaction and microsegregation potential of the major element are similar to those of Inconel 718. Zareie Rajani et al. ${ }^{[12]}$ compared the corrosion behavior of fusion cladding and explosive cladded of Inconel 625 . They found that a single fusion layer does not exhibit protection potential. However, this adverse property could be changed by adding more fusion layers. Using pulsed plasma arc, F. J. Xu et al. ${ }^{[6]}$ investigated the microstructure and mechanical properties of

Received date: October 11, 2015

Foundation item: Innovation Foundation of Southwest Petroleum University (CX2014BY05); Open Foundation of Education Department Key Laboratory of Oil and Gas Equipment (OGE201401-01)

Corresponding author: Liu Shaohu, Ph. D., Mechanical Engineering College, Yangtze University, Jingzhou 434023, P. R. China, E-mail: liushaoh@ 126.com Copyright $($ ) 2016, Northwest Institute for Nonferrous Metal Research. Published by Elsevier BV. All rights reserved. 
an Inconel 625 sample. To predict the process characteristics for varying process parameters, T. E. Abioye et al. ${ }^{[7,13]}$ established a process map for laser deposition of Inconel 625. The outcomes revealed that the process parameters of the laser have a substantial effect on the clad beads characteristics.

The hot wire pulsed TIG process is a widely used technique, which inherits the benefits of pulsed TIG. The advantages were usually reported including high efficiency, lower heat input, compatibility with a wide range of materials, and good quality of the weld bead ${ }^{[14,15]}$. Also, the moderate investment of equipment and low running costs further boost the widespread application of the hot wire pulsed TIG in surface modification. However, the relevant published information regarding the weld overlay of Inconel 625 using hot wire pulsed TIG is limited. In the present study, to establish empirical mathematical models between process parameters and formation quality of the single clad beads, a number of clad beads were deposited on the substrate of AISI 4130. Then, the process parameters were optimized using RSM. Multi-track two-layer weld overlay was obtained based on the optimized process parameters. Microstructure evolution and corrosion performance of the weld overlay were also investigated in detail.

\section{Experiment}

The substrate material was AISI 4130 steel plates with dimensions of $150 \mathrm{~mm} \times 150 \mathrm{~mm} \times 25 \mathrm{~mm}$. It had been heat treated with hardening and tempering. The filler wire was nickel-based alloy ERNiCrMo-3 with a $1.2 \mathrm{~mm}$ diameter. The nominal chemical compositions of the substrate and the filler wire, as received, are shown in Table 1 . To remove oxidation and other contaminants, the working surface of the substrate was polished with Sic paper and cleaned with acetone. Clad beads were deposited on the substrate using a Fronius hot wire pulsed TIG system. During the welding procedure, a circuit was formed between the filler wire and the substrate, when the wire contacted with the substrate. Therefore, the filler was preheated by resistance heat. Pure argon was selected as shielding gas with a flow rate of $15 \mathrm{~L} / \mathrm{min}$. The diameters of the jet nozzle and tungsten electrode were 12.5 and $3.2 \mathrm{~mm}$, respectively.

Preliminary experiments were conducted to optimize the process parameters based on five factors, five levels CCD. In general, welding speed $\left(V_{\mathrm{S}}\right)$ and pulse current parameters have significant effects on heat input, which determines the formation quality of the clad beads ${ }^{[16-19]}$. Fig.1 shows the schematic of the pulse current parameters including peak current $\left(I_{\mathrm{p}}\right)$, base current $\left(I_{\mathrm{b}}\right)$, pulse time $\left(t_{\mathrm{p}}\right)$ and base time $\left(t_{b}\right)$. Based on the known parameters, pulse current frequency $f=1 /\left(t_{\mathrm{p}}+t_{\mathrm{b}}\right)$ and duty cycle of pulse current duration $\delta=t_{\mathrm{p}} /\left(t_{\mathrm{p}}+t_{\mathrm{b}}\right)$ can be deduced ${ }^{[18]}$. Consequently, the key independent parameters chosen for investigation are welding speed $\left(V_{\mathrm{S}}\right)$, peak current $\left(I_{\mathrm{p}}\right)$, base current $\left(I_{\mathrm{b}}\right)$, frequency $(f)$ and duty cycle $(\delta)$. The variables and their corresponding levels are listed in Table 2. In all trials, hot wire current, arc voltage and wire feed rate were maintained at $70 \mathrm{~A}, 13.5 \mathrm{~V}$ and $2 \mathrm{~m} / \mathrm{min}$, respectively. By modeling reliable empirical models between the variables and responses, the RSM method provided the optimized window of parameters for the specific formation quality. Next, the multi-track two-layer weld overlay was deposited to analyze the microstructure and to evaluate the corrosion performance.

The metallographic specimens of the multi-track two-layer weld overlay were sectioned along longitudinal section, which was parallel to the welding direction. Standard metallographic procedures involving polishing with emery sheets of $\mathrm{SiC}$ with grit size varying from 220 to 1000 , followed by disc polishing using alumina and distilled water were employed to obtain

Table 1 Chemical composition of the substrate and filler wire (wt\%)

\begin{tabular}{ccccccccccc}
\hline Element & $\mathrm{C}$ & $\mathrm{Cr}$ & $\mathrm{Ni}$ & $\mathrm{Ti}$ & $\mathrm{Fe}$ & $\mathrm{Mo}$ & $\mathrm{Al}$ & $\mathrm{Nb}$ & $\mathrm{Others}$ \\
\hline Substrate & 0.29 & 0.99 & 0.02 & 0.006 & $\mathrm{Bal}$ & 0.175 & 0.006 & - \\
Filler wire & 0.01 & 22.65 & 64.24 & 0.2 & 0.32 & 8.73 & 0.16 & 3.53 & 0.16 \\
\hline
\end{tabular}

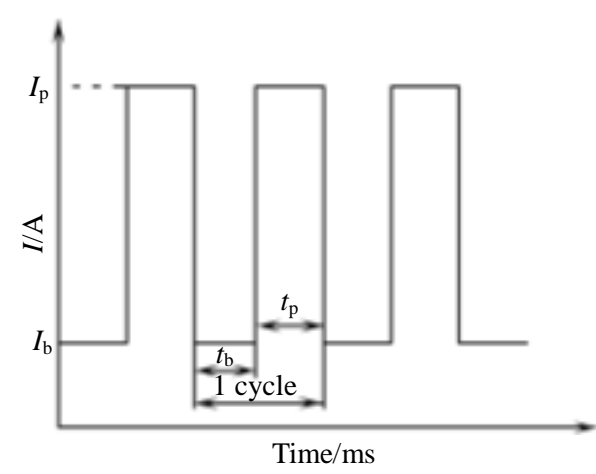

Fig.1 Schematic of the pulsed TIG process parameters mirror samples. Next, the samples were etched electrolytically in a mixture liquid $\left(12 \mathrm{~mL} \mathrm{H}_{3} \mathrm{PO}_{4}+40 \mathrm{~mL} \mathrm{HNO}+48 \mathrm{~mL}\right.$ $\mathrm{H}_{2} \mathrm{SO}_{4}$ ) at $6 \mathrm{~V}$ for about $15 \mathrm{~s}{ }^{[20]}$. The microstructure of the cladding was observed using an RX50M metallographic microscope.

To analyze the effects of the chemical composition on the corrosion property, samples were sectioned at two different locations. The distances between cutting surfaces and substrate working surface were 2.4 and $5.0 \mathrm{~mm}$. The testing surface dimension of all samples was $10 \mathrm{~mm} \times 10 \mathrm{~mm}$. For testing accuracy, the samples were prepared using standard metallographic procedures to guarantee consistent surface roughness. Then, the testing surface was cleaned in distilled 
Table 2 Process variables and their corresponding levels

\begin{tabular}{cccccc}
\hline Variables & \multicolumn{5}{c}{ Levels of variables } \\
\cline { 2 - 6 } & -2 & -1 & 0 & 1 & 2 \\
\hline Welding rate, $V_{\mathrm{s}} / \mathrm{cm} \cdot \mathrm{min}^{-1}$ & 12 & 15 & 18 & 21 & 24 \\
Peak current, $I_{\mathrm{P}} / \mathrm{A}$ & 210 & 220 & 230 & 240 & 250 \\
Base current, $I_{\mathrm{b}} / \mathrm{A}$ & 90 & 95 & 100 & 105 & 110 \\
Pulsed frequency, $f / \mathrm{H}_{\mathrm{Z}}$ & 1 & 2 & 3 & 4 & 5 \\
Duty cycle, $\delta$ & 0.3 & 0.4 & 0.5 & 0.6 & 0.7 \\
\hline
\end{tabular}

water and thoroughly dried in air. The chemical composition of the samples was determined using energy dispersive spectrometer (EDS), prior to the corrosion performance tests. The corrosion resistance was estimated using the potentiodynamic polarization testing in a $3.5 \mathrm{wt} \% \mathrm{NaCl}$ solution at room temperature. A standard three-electrode cell was used with a platinum plate as counter electrode, and a $\mathrm{Ag} / \mathrm{AgCl}$ electrode as reference electrode. The working electrode was samples prepared from the substrate and weld overlay. Using the Potentiostat (Autolab PGSTAT302N), potentiodynamic polarization scan was performed for each of the samples with a sweep rate of $20 \mathrm{mV} / \mathrm{min}$ from their open circuit potential. The potential was scanned over the range of $-200 \mathrm{mV}$ to $1500 \mathrm{mV}$. The corresponding current flow between the working and counter electrodes was recorded for each scan.

\section{RSM Optimization Results}

\subsection{Mathematical modeling and adequacy checking}

The formation quality of the clad beads was represented by the weld height $\left(Y_{1}\right)$, weld width $\left(Y_{2}\right)$, and dilution $\left(Y_{3}\right)$, as illustrated in Fig.2. The dilution can be expressed using the following equation ${ }^{[20,21]}$ :

$$
Y_{3}=\frac{A_{\mathrm{W}}}{A+A_{\mathrm{W}}}
$$

where, $A_{\mathrm{W}}$ and $A$ are the area of molten substrate and clad beads, respectively. The weld width affects the number of weld tracks. However, the weld height and dilution have significant influence on the cladding layers and performance. In production process, the acceptable dimensions of the weld beads depend on the specific working condition. For large dimensional workpieces, the ability to deposit large weld beads with minimal heat input is expected. But, smaller clad

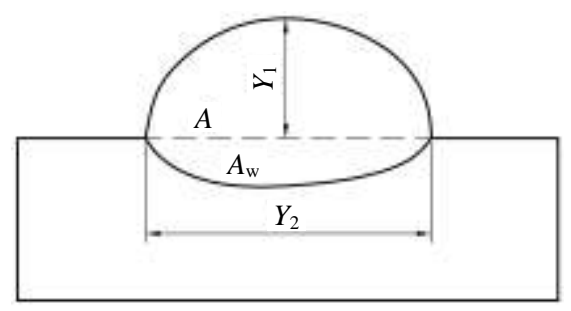

Fig.2 Geometric parameters of the clad bead beads are desirable for thinner and smaller components. In any case, the minimal dilution is expected, because the performance of the weld overlay degenerates with the increase in dilution. In this study, a relatively large clad width, reasonable height and minimal dilution are desired. The design table and corresponding responses of the clad beads are given in Table 3.

A second order polynomial equation was used to fit the relationship between the inputs and responses. The corresponding function for five factors can be expressed as follows ${ }^{[22,23]}$ :

$$
Y_{i}=a_{0}+\sum_{j=1}^{5} \beta_{j} x_{j}+\sum_{\substack{j=1 \\ j<k}}^{5} \beta_{k j} x_{k} x_{j}+\sum_{j=1}^{5} \beta_{j j} x_{j}^{2}
$$

where, $Y_{i}$ is the response, $a_{0}$ is the constant term, $x_{j}$ is the value of the input variable, $\beta_{j}$ is the linear term coefficient, $\beta_{k j}$ is the interaction term coefficients, and $\beta_{j j}$ is the quadratic coefficient. Design-expert ${ }^{\circledR}$ statistical analysis software was employed to calculate the coefficients of the polynomials. The stepwise method was used to establish the relationships between the input variables and responses. In this procedure, the terms with a $p$-value greater than the critical value 0.05 were removed. Because a $p$-value greater than 0.05 suggests that the influence of the corresponding term is insignificant ${ }^{[24]}$ The final mathematical models with nature forms of the significant variables are presented in Eqs. (3) (5).

$$
\begin{aligned}
Y_{1}= & 23.57-0.301 V_{\mathrm{s}}-0.064 I_{\mathrm{p}}-0.13 I_{\mathrm{b}}+0.144 f+4.5 \times 10^{-4} I_{\mathrm{p}} I_{\mathrm{b}}- \\
& 14.08 \delta+0.03 I_{\mathrm{p}} \delta+0.05 I_{\mathrm{b}} \delta+5.59 \times 10^{-3} V_{\mathrm{s}}^{2}-0.016 f^{2}+1.53 \delta^{2} \\
Y_{2}= & 3.581-0.395 V_{\mathrm{s}}+0.03 I_{\mathrm{p}}+3.083 \times 10^{-3} I_{\mathrm{b}}-0.508 f+ \\
& 4.054 \delta+8.83 \times 10^{-3} V_{\mathrm{s}}^{2}+0.069 f^{2} \\
Y_{3}= & -2.167+6.97 \times 10^{-3} V_{\mathrm{s}}+4.313 \times 10^{-3} I_{\mathrm{p}}+9.85 \times 10^{-3} I_{\mathrm{b}}- \\
& 0.0123 f+4.789 \delta-6.875 \times 10^{-3} I_{\mathrm{p}} \delta-0.021 I_{\mathrm{b}} \delta-0.883 \delta^{2}
\end{aligned}
$$

The adequacy of the models was checked using the analysis of variance technique (ANOVA). The testing results are shown in Table 4 . The $p$-value is the probability value used to test the hypothesis. At a 95\% confidence level, $p$-value should be less than the critical value of $0.05^{[20]}$. The relationships established are highly significant, because the $p$-value of all the models is much less than the critical value ${ }^{[25,26]}$. However, some terms with $p$-value greater than 0.05 were still retained in the regression equations for accuracy. The lack of fit tests demonstrates that the lack of fit is insignificant and that the models fit the data well ${ }^{[19]}$. All of the values of $R^{2}$ are greater than 0.9 , meaning that a high correlation exists between the measured and the predicted values ${ }^{[25]}$. It is also observed that the Adj. $R^{2}$ is reasonably consistent with the pre. $R^{2}$ So, all of the adequacy tests indicate that the models are significant and rational.

\subsection{Formation quality optimization}

A numerical optimization method was selected to optimize the process parameters. Table 5 summarizes the criteria used for optimization of the formation quality. $Y_{3}$ was given the top 
Table 3 Design of experiment and responses

\begin{tabular}{|c|c|c|c|c|c|c|c|c|}
\hline \multirow{2}{*}{ Run No. } & \multicolumn{5}{|c|}{ Process parameters } & \multicolumn{3}{|c|}{ Responses } \\
\hline & $V_{\mathrm{s}}$ & $I_{\mathrm{p}}$ & $I_{\mathrm{b}}$ & $f$ & $\delta$ & $Y_{1}$ & $Y_{2}$ & $Y_{3}$ \\
\hline 1 & 0 & 2 & 0 & 0 & 0 & 2.2 & 8.38 & 0.272 \\
\hline 2 & -1 & -1 & 1 & -1 & -1 & 2.66 & 7.72 & 0.213 \\
\hline 3 & 1 & 1 & 1 & -1 & -1 & 1.95 & 7.55 & 0.288 \\
\hline 4 & 1 & 1 & -1 & -1 & 1 & 1.84 & 8.34 & 0.327 \\
\hline 5 & 2 & 0 & 0 & 0 & 0 & 1.88 & 7.61 & 0.292 \\
\hline 6 & -1 & 1 & 1 & -1 & 1 & 2.52 & 8.74 & 0.253 \\
\hline 7 & 0 & 0 & 0 & 0 & 0 & 2.2 & 7.51 & 0.272 \\
\hline 8 & 1 & -1 & 1 & 1 & -1 & 2.14 & 6.6 & 0.224 \\
\hline 9 & 0 & 0 & 2 & 0 & 0 & 2.3 & 7.41 & 0.221 \\
\hline 10 & -1 & -1 & -1 & -1 & 1 & 2.5 & 8.3 & 0.253 \\
\hline 11 & 0 & 0 & 0 & -2 & 0 & 2.1 & 8.15 & 0.301 \\
\hline 12 & 0 & -2 & 0 & 0 & 0 & 2.38 & 7.06 & 0.23 \\
\hline 13 & 0 & 0 & 0 & 2 & 0 & 2.29 & 7.44 & 0.227 \\
\hline 14 & 0 & 0 & 0 & 0 & 0 & 2.23 & 7.48 & 0.259 \\
\hline 15 & -1 & 1 & 1 & 1 & -1 & 2.62 & 8.1 & 0.214 \\
\hline 16 & 0 & 0 & 0 & 0 & 2 & 2.19 & 8.38 & 0.284 \\
\hline 17 & -1 & 1 & -1 & -1 & -1 & 2.63 & 8.01 & 0.215 \\
\hline 18 & 1 & 1 & 1 & 1 & 1 & 2.05 & 8.19 & 0.267 \\
\hline 19 & 0 & 0 & 0 & 0 & 0 & 2.26 & 7.49 & 0.273 \\
\hline 20 & 0 & 0 & 0 & 0 & -2 & 2.45 & 6.92 & 0.155 \\
\hline 21 & -1 & 1 & -1 & 1 & 1 & 2.54 & 8.69 & 0.254 \\
\hline 22 & 0 & 0 & 0 & 0 & 0 & 2.29 & 7.69 & 0.255 \\
\hline 23 & -1 & -1 & 1 & 1 & 1 & 2.57 & 8.33 & 0.247 \\
\hline 24 & -1 & -1 & -1 & 1 & -1 & 2.88 & 7.24 & 0.173 \\
\hline 25 & 1 & -1 & -1 & 1 & 1 & 2.05 & 7.82 & 0.303 \\
\hline 26 & 1 & -1 & 1 & -1 & 1 & 1.9 & 7.8 & 0.29 \\
\hline 27 & 0 & 0 & 0 & 0 & 0 & 2.25 & 7.72 & 0.262 \\
\hline 28 & 1 & 1 & -1 & 1 & -1 & 2.04 & 7.45 & 0.239 \\
\hline 29 & 0 & 0 & 0 & 0 & 0 & 2.26 & 7.7 & 0.261 \\
\hline 30 & 1 & -1 & -1 & -1 & -1 & 2.11 & 6.73 & 0.228 \\
\hline 31 & -2 & 0 & 0 & 0 & 0 & 3.04 & 8.06 & 0.213 \\
\hline 32 & 0 & 0 & -2 & 0 & 0 & 2.24 & 7.45 & 0.247 \\
\hline
\end{tabular}

Table 4 Statistical validity of the regression models developed

\begin{tabular}{|c|c|c|c|c|c|}
\hline \multicolumn{2}{|c|}{$Y_{1}$} & \multicolumn{2}{|c|}{$Y_{2}$} & \multicolumn{2}{|c|}{$Y_{3}$} \\
\hline Source & $p$-value & Source & $p$-value & Source & $p$-value \\
\hline Model & $<0.0001$ & Model & $<0.0001$ & Model & $<0.0001$ \\
\hline$V_{\mathrm{S}}$ & $<0.0001$ & $V_{S}$ & $<0.0001$ & $V_{\mathrm{S}}$ & $<0.0001$ \\
\hline$I_{\mathrm{P}}$ & $<0.0001$ & $I_{P}$ & $<0.0001$ & $I_{P}$ & 0.0033 \\
\hline$I_{\mathrm{b}}$ & 0.7246 & $I_{b}$ & 0.023 & $I_{\mathrm{b}}$ & 0.4604 \\
\hline$f$ & $<0.0001$ & $f$ & $<0.001$ & $f$ & 0.0001 \\
\hline$\delta$ & $<0.0001$ & $\delta$ & $<0.0001$ & $\delta$ & $<0.0001$ \\
\hline$I_{\mathrm{p}} I_{\mathrm{b}}$ & 0.0162 & $V_{S}^{2}$ & 0.027 & $I_{\mathrm{p}} \delta$ & 0.0462 \\
\hline$I_{\mathrm{p}} \delta$ & 0.0023 & $f^{2}$ & 0.051 & $I_{\mathrm{b}} \delta$ & 0.0046 \\
\hline$I_{\mathrm{b}} \delta$ & 0.0085 & & & $\delta^{2}$ & 0.0012 \\
\hline$V_{\mathrm{S}}^{2}$ & $<0.0001$ & & & & \\
\hline$f^{2}$ & 0.0196 & & & & \\
\hline$\delta^{2}$ & 0.00246 & & & & \\
\hline Lack of fit & 0.399 & Lack of fit & 0.118 & Lack of fit & 0.0706 \\
\hline$R^{2}=0.9905$ & $\operatorname{Adj} \cdot R^{2}=0.9853$ & $R^{2}=0.902$ & Adj. $R^{2}=0.878$ & $R^{2}=0.908$ & Adj. $R^{2}=0.876$ \\
\hline \multicolumn{2}{|c|}{ Pred. $R^{2}=0.976$} & \multicolumn{2}{|c|}{ Pred. $R^{2}=0.758$} & \multicolumn{2}{|c|}{ Pred. $R^{2}=0.813$} \\
\hline
\end{tabular}

priority among the responses because dilution is more detrimental to the performance of the cladding. However, dilution is a necessary factor for metallurgical bonding between the cladding and the substrate. Some of the predicted 
results are listed in Table 6, and the one with most desirable result is selected. A conformity trial was conducted with the same experimental conditions to verify the accuracy of the predicted value. The results are also listed in Table 6 . There are slight differences between the predicted and experimental values, but the relationships are reasonable.

Based on the optimized process parameters, a multi-track two-layer weld overlay was deposited. The length of each track is approximately $125 \mathrm{~mm}$, and the overlap rate of adjacent tracks is 0.4 . The overlap results in the later weld partly depositing in the previous weld. So, the height of the final weld overlay is not integer times of the first pass. The macroscopic morphology of the weld overlay is presented in Fig.3. It can be seen that the surface of the weld overlay is relatively smooth with no macroscopic defects.

\section{Microstructure and Corrosion Performance}

\subsection{Microstructure characterization}

Fig. 4 shows the longitudinal sectional microstructure of the Inconel 625 weld overlay. It indicates that a good metallurgical bond between the weld overlay and substrate is formed, and that the weld overlay is dense and crack-free. The weld overlay consists of a large number of columnar dendrites, which grow epitaxially from the substrate. Fig.4a presents the microstructure at the bottom of the weld overlay. It demonstrates that there are a few planner crystals and cellular dendrites distributed in the fusion region. The columnar dendrites grow along the deposition direction. Unlike the fusion zone, planner crystals and cellular dendrites do not appear in the interfaces between the adjacent layers, as shown in Fig.4b. At the uppermost of the weld overlay, there is a thin layer, where the dendrites grow parallel to the substrate, as displayed in Fig.4d. These dendrites are known as steering dendrites. Therefore, the microstructure morphology evolution, from the bottom to surface, is planner crystals, cellular dendrites, columnar dendrites, equiaxed and steering dendrites.

The grain morphology transformations are due to the combined effects of temperature gradients $(G)$ and grain growth rate $(R)$ of the molten pool. With the arc igniting and wire feeding in the cladding process, a molten pool will be established and then solidified after the electric arc is moved. Since the maximum $G$ and minimum $R$ occur at the clad-substrate interface, there will be few planar crystals generated at first, as shown in Fig.4a. With the movement of solid/liquid interface, the grain morphology changes from planner crystals into cellular dendrites because of the decreasing $G$ and the increasing $R$. When $G$ decreases to a certain value, the solidification microstructure changes into

Table 5 Criterion used for the RSM numerical optimization

\begin{tabular}{ccccccc}
\hline \multirow{2}{*}{$\begin{array}{c}\text { Input variable } \\
\text { or response }\end{array}$} & Criterion & \multicolumn{2}{c}{ Limit } & \multicolumn{2}{c}{ Weight } & Important \\
\cline { 3 - 6 } & & Lower & Upper & Lower & Upper & \\
\hline$X_{1}$ & Is in range & 12 & 24 & 1 & 1 & 3 \\
$X_{2}$ & Is in range & 210 & 240 & 1 & 1 & 3 \\
$X_{3}$ & Is in range & 90 & 110 & 1 & 1 & 3 \\
$X_{4}$ & Is in range & 1 & 5 & 1 & 1 & 3 \\
$X_{5}$ & Is in range & 0.3 & 0.7 & 1 & 1 & 3 \\
$Y_{1}$ & Is in range & 2 & 2.5 & 1 & 1 & 3 \\
$Y_{2}$ & Maximum & 6 & 8.47 & 1 & 1 & 2 \\
$Y_{3}$ & Minimum & 0.1 & 0.327 & 1 & 1 & 5 \\
\hline
\end{tabular}

Table 6 RSM numerical optimization and experimental results

\begin{tabular}{ccccccccccc}
\hline & $V_{\mathrm{S}}$ & $I_{\mathrm{p}}$ & $I_{\mathrm{b}}$ & $f$ & $\delta$ & $Y_{1}$ & $Y_{2}$ & $Y_{3}$ & Desirability \\
\hline \multirow{5}{*}{ Predicted } & 17.45 & 239.94 & 90 & 4.98 & 0.3 & 2.5 & 7.241 & 0.126 & 0.753 & Selected \\
& 18.29 & 234.97 & 92.17 & 4.99 & 0.31 & 2.49 & 7.018 & 0.119 & 0.731 & - \\
& 17.05 & 240 & 103.08 & 5 & 0.32 & 2.46 & 7.314 & 0.619 & 0.643 & - \\
\hline Experimental & 18 & 240 & 90 & 5 & 0.3 & 2.62 & 7.46 & 0.118 & - & \\
\hline
\end{tabular}

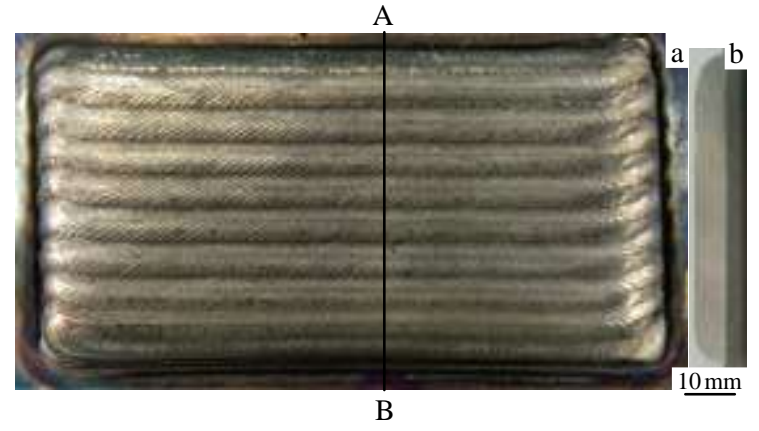

Fig.3 Macroscopic morphology of the Inconel 625 cladding: (a) top view, (b) A-B cross sectional view dendrite crystals, and then it grows into columnar dendrites. Because the substrate plays a role as heat sink and the positive temperature gradients towards material deposition direction, the columnar dendrites show a certain directional growth, as shown in Fig.4a 4c. When the bottom of the molten pool is solidifying, the top of the molten pool is also solidifying into steering dendrites because of the change in the principal heat flux direction, which is due to the result of contacting air and previous solidified track. Owing to partial remelting of the upper portion of the previous layer, steering dendrites do not appear in the interior of the coating, as shown in Fig.4b. There are also no planner crystals and cellular crystals in the interface 


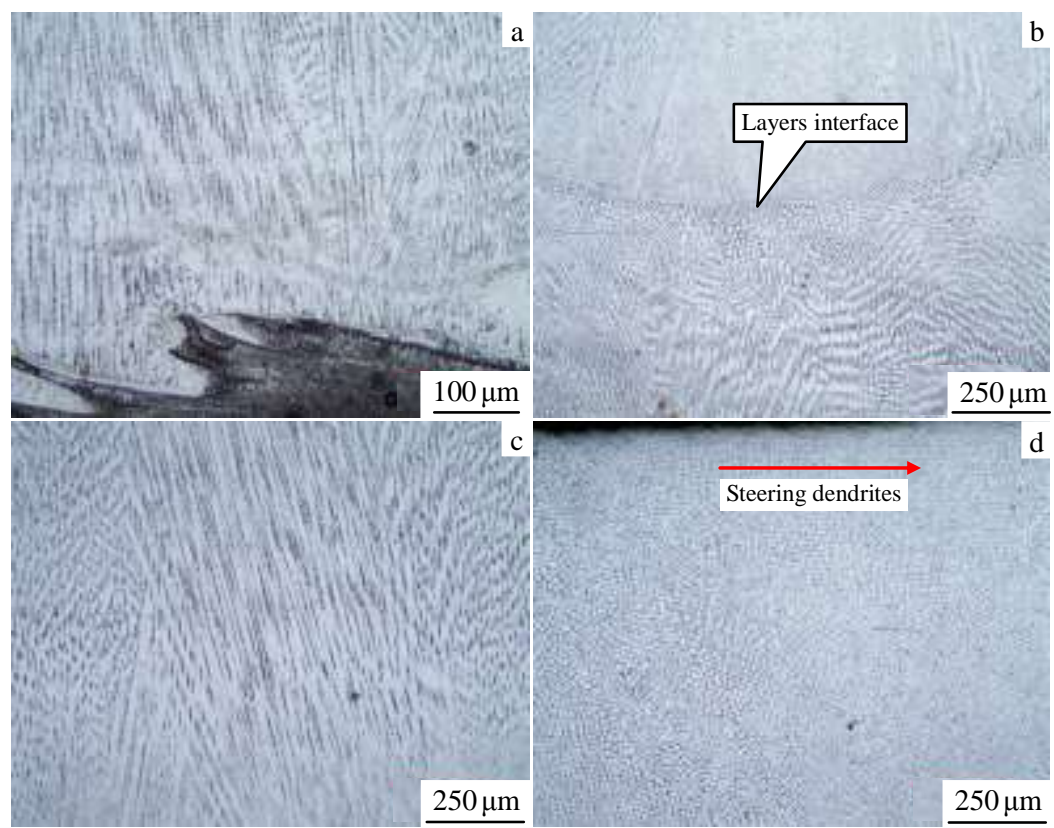

Fig.4 Microstructure of weld overlay: (a) at the bottom, (b) at the overlapping zone of tracks, (c) in the upper part, and (d) at the top region

between layers. This attributes to the rapid solidification rate, which gives the grains between layers insufficient time to establish the "flat interface growth mode". With the solid/liquid interface further away from the bottom to top, the value of $G / R$ decreases and the equilibrium for the directional solidification is breakdown. Therefore, many equiaxed grains distribute in the upper portion of the clad bead, as indicated in Fig.4d.

\subsection{Electrochemical corrosion tests}

The corrosion potential $\left(E_{\text {corr }}\right)$, passive current density $\left(I_{\mathrm{p}}\right)$ and breakdown potential $\left(E_{\mathrm{b}}\right)$ are the primary parameters to evaluate the corrosion resistance of materials. In general, materials that exhibit a high corrosion potential possess better corrosion resistance ${ }^{[27]}$. The passive current density is considered to be a positive characteristic in uniform corrosion resistance, because the formation of a passive film at low current density prevents severe loss of materials at higher current densities ${ }^{[7]}$. The breakdown potential reflects the ability of materials to resist against the production of local defects on the passive film ${ }^{[28]}$. A higher breakdown potential can hinder the damage to the protective layer at low applied electrochemical voltages. Fig.5 illustrates the potentiodynamic polarization curves of the Inconel 625 weld overlay and substrate. The corresponding parameters determined from the curves are listed in Table 7. Also, the corrosion data of the wrought Inconel 625 under the same testing conditions as found in the literature are also summarized in Table $7^{[7]}$.

As illustrated in Fig.5, the shape of the potentiodynamic polarization curves shows that the substrate exhibits an active dissolution behavior, because the anodic current density steadily increases when the potential shifts in the noble

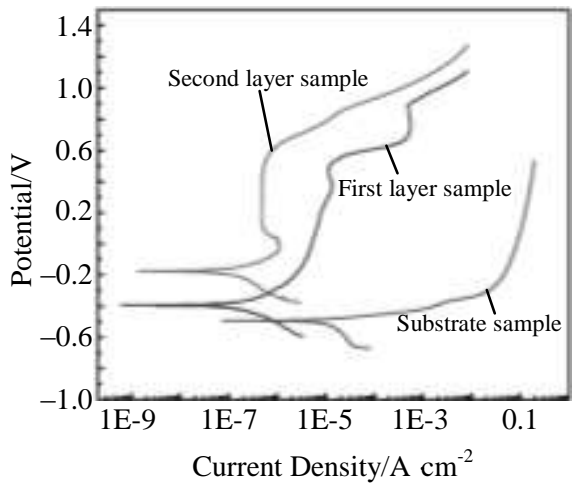

Fig.5 Potential polarization curves of weld overlay and substrate

Table 7 Corrosion parameters of the Inconel 625 weld overlay and wrought Inconel 625

\begin{tabular}{cccc}
\hline Samples & $E_{\text {corr }} / \mathrm{mV}$ & $I_{\mathrm{p}} / \times 10^{-3} \mathrm{~mA}$ & $E_{\mathrm{b}} / \mathrm{mV}$ \\
\hline Substrate & -492 & - & - \\
Cladding (first layer) & -393 & 11.8 & 514 \\
Cladding (second layer) & -174 & 0.4850 & 542 \\
Wrought Inconel 625 & -264 & 0.470 & 600 \\
\hline
\end{tabular}

direction. While, the first layer sample displays a repassive behavior. In addition, the second layer sample shows a wide and stable passive region, which implies that the passive film is very stable. The passive behavior of the cladding sample can be attributed to the high chromium content ${ }^{[28,29]}$. Moreover, in their transpassive region, the lower gradient of the current density against the potential demonstrates that permanent damage can not form on the passive layer. Therefore, the corrosion damage on the cladded samples is uniform. 
Table 8 Major chemical composition of the weld overlay (wt \%)

\begin{tabular}{cccccc}
\hline Samples & $\mathrm{Ni}$ & $\mathrm{Cr}$ & $\mathrm{Fe}$ & $\mathrm{Mo}$ & $\mathrm{Nb}$ \\
\hline First layer & 57.93 & 20.66 & 8.13 & 8.29 & 2.67 \\
Second layer & 61.82 & 21.89 & 1.81 & 9.22 & 3.52 \\
\hline
\end{tabular}

According to Table 7, the corrosion performance of the second layer sample is similar to that of the wrought Inconel 625 because of the similar characteristic parameters. The polarization curves and corresponding parameters of the samples demonstrate that the first layer sample has lower corrosion potential, higher passive current density and lower breakdown potential. A higher passivation current density will delay the formation of a protective film, which consequently increases the uniform corrosion attack. In addition, any damage in the passive film would aggravate the corrosion resistance and accelerate the nonuniform form of corrosion, such as pitting. The lower breakdown potential suggests that pitting or crevice corrosion will occur at a smaller relative potential. In other words, the first layer sample exhibits poor corrosion performance. This detrimental effect can be mainly attributed to the Fe content in the weld overlay, as shown in Table 8. An excessive amount of $\mathrm{Fe}$ is considered to be a contaminant element for the dilution effect. Although the dilution can enhance the bond of the cladding layers, it aggravates the corrosion resistance of the materials through the contamination elements.

\section{Conclusions}

1) The hot wire pulsed TIG process is suitable for cladding of Inconel 625 , with ability to produce pore-and crack-free clad beads. This process can be used for cladding and repairing components manufactured from Inconel 625 .

2) The models between the process parameters and formation quality of the clad beads are adequate and significant. Moreover, the conformity test indicates that the models can predict the responses with high accuracy.

3) The microstructure evolution, from the bottom to surface, is planner crystals, cellular dendrites, columnar dendrites, equiaxed and steering dendrites. Some planar crystals and cellular dendrites are distributed in the fusion zone. Meanwhile, the grains distributions in the upper and top portion of the weld overlay are equiaxed grains and steering dendrites, respectively.

4) Compared with the first layer sample, the second layer sample of the cladding shows better corrosion performance. Additionally, the corrosion performance of the second layer is close to that of the wrought Inconel 625. These suggest that components made of AISI 4130 can be well protected from corrosion by the Inconel 625 weld overlay.

5) An excessive amount of $\mathrm{Fe}$ is detrimental to the corrosion performance of the weld overlay. However, the content of Fe declines rapidly by adding cladding layer. At the second layer surface, the element content is highly similar to the filler wire.

Acknowledgments: The authors acknowledge the Chongqing Xintai Petroleum Machinery Company for support of the cladding experiment.

\section{References}

1 Mohammadi Zahrani E, Alfantazi A M. Corrosion Science [J], 2014, 85(0): 60

2 Dinda G P, Dasgupta A K, Mazumder J. Materials Science and Engineering $A[\mathrm{~J}], 2009,509(1-2): 98$

3 Li Defu, Guo Shengli, Wu Zhigang et al. Rare Metal Materials and Engineering[J], 2011, 40(S3): 95 (in Chinese)

4 Puppala Ganesh, Moitra Aniruddha, Sathyanarayanan S et al. Materials \& Design[J], 2014, 59(3): 509

5 Maltin Charles A, Galloway Alexander M, Mweemba Martin. Metallurgical and Materials Transactions A[J], 2014, 45(8): 3519

6 Xu F J, Lv Y H, Xu B S et al. Materials \& Design[J], 2013, 45(2): 446

7 Abioye T E, McCartney D G, Clare A T. Journal of Materials Processing Technology[J], 2015, 217(2): 232

8 Paul C P, Ganesh P, Mishra S K et al. Optics \& Laser Technology[J], 2007, 39(4): 800

9 Xu Fujia, Lv Yaohui, Liu Yuxin et al. Journal of Materials Science \& Technology[J], 2013, 29(5): 480

10 Bhargava P, Paul C P, Premsingh C $\mathrm{H}$ et al. Advances in Manufacturing[J], 2013, 1(4): 305

11 Dupont J N. Metall Mater Trans A[J], 1996, 27A: 3612

12 Zareie Rajani H R, Akbari Mousavi S A A, Madani Sani F. Materials \& Design[J], 2013, 43(3): 467

13 Abioye T E, Folkes J, Clare A T. Journal of Materials Processing Technology[J], 2013, 213(12): 2145

14 Wang Fude, Williams Stewart, Rush Matthew. The International Journal of Advanced Manufacturing Technology[J], 2011, 57(5-8): 597

15 Madadi F, Ashrafizadeh F, Shamanian M. Journal of Alloys and Compounds[J], 2012, 510(1): 71

16 Pal Kamal, Pal Surjya K. Journal of Materials Engineering and Performance [J], 2011, 20(6): 918

17 Mirzaei M, Arabi Jeshvaghani R, Yazdipour A et al. Materials \& Design[J], 2013, 51: 709

18 Hadadzadeh Amir, Ghaznavi Majid Mahmoudi, Kokabi Amir Hossein. Materials \& Design[J], 2014, 55: 335

19 He Huan, Yang Chunli, Chen Zhe et al. Acta Metallurgica Sinica [J], 2014, 27(6): 1012

20 Ola O T, Doern F E. Materials \& Design[J], 2014, 57: 51

21 Kumar A, Sundarrajan S. The International Journal of Advanced Manufacturing Technology[J], 2009, 42(1-2): 118

22 Wang Jin, Wang Huiping, Wang Xiaojie et al. Optics \& Laser Technology[J], 2015, 66(1): 15

23 Senthilkumar B, Kannan T. Measurement [J], 2015, 62: 127

24 Karthikeyan R, Balasubramanian V. The International Journal of Advanced Manufacturing Technology[J], 2010, 51(1-4): 173 
25 Wen Peng, Feng Zhenhua, Zheng Shiqing. Optics \& Laser Technology[J], 2015, 65(1): 180

26 Gomes J H F, Paiva A P, Costa S C et al. European Journal of Operational Research[J], 2013, 226(3): 522

27 Wang Shaogang, Ma Qihui, Li Yan. Materials \& Design[J],
2011, 32(2): 831

28 Mortezaie A, Shamanian M. International Journal of Pressure Vessels And Piping[J], 2014, 116: 37

29 Ray A, Arora K S, Lester S et al. Journal of Materials Processing Technology[J], 2014, 214(8): 1566

\title{
热丝脉冲 TIG 堆焊 Inconel 625 成型质量优化与耐腐蚀性能研究
}

\author{
郭龙龙 ${ }^{1}$, 郑华林 ${ }^{1}$, 刘少胡 ${ }^{2}$, 李悦钦 ${ }^{1}$, 徐小东 ${ }^{1}$, 冯春宇 ${ }^{1}$ \\ (1. 西南石油大学, 四川 成都 610500) \\ (2. 长江大学, 湖北 荆州 434023)
}

\begin{abstract}
摘 要: 基于中心复合试验设计方法, 采用热丝脉冲 TIG (tungsten inert gas arc welding) 工艺, 在 AISI 4130 基体上堆焊 Inconel 625 合金 层。借助响应面法建立了焊缝几何特征与工艺参数之间的数学模型。根据优化后的工艺参数, 获得了平坦、连续、无缺陷的多道两层堆 焊层。堆焊层微观组织主要由柱状晶组成, 在融合界面附近存在少量的平面晶与胞状晶, 其顶部组织为等轴晶与转向晶。利用动态极化 曲线法对基体与堆焊层的耐腐蚀性能进行了评价。结果表明：堆焊层的耐腐蚀性随着 $\mathrm{Fe}$ 含量的增加而降低，但增加堆焊层的层数可以 显著提高耐腐蚀性能。而且, 两层堆焊层试样与铸态 Inconel 625 的耐腐蚀性能基本相当。
\end{abstract}

关键词: Inconel 625; 响应面法; 微观组织; 堆焊; 动态极化曲线

作者简介: 郭龙龙, 男, 1988 年生, 博士生, 西南石油大学机电工程学院, 四川 成都 610500, 电话: 028-83033697, E-mail: 810396447@qq.com 